\title{
COMMENTARY
}

\section{COVID-19: A Burden on the Indian Healthcare System}

\author{
Naushaba Akhtar,' Shakti Rath ${ }^{2}$
}

Department of Public Health, Asian Institute of Public Health, Bhubaneswar, Odisha, India.

Central Research Laboratory, Institute of Dental Sciences, Siksha 'O' Anusandhan (Deemed to be University), Bhubaneswar, Odisha, India.

Correspondence to: Dr. Shakti Rath, Email: dr.shaktirath@gmail.com, ORCiD: 0000-0003-3249-9080

\section{ABSTRACT}

The COVID-19 cases and the death toll are increasing in India with time so is the demand for an improved healthcare system. This critical situation demands a huge medical infrastructure with sufficient medical personnel. This pandemic has also led to an increase in demand for medical equipment in different parts of India, which is causing clinical consternations during treatment procedures. This paper confers the current situation being faced by the healthcare system in India and provide a descriptive analysis of the current situation, which would act as a situational guide for the policymakers. This paper has also reviewed recent literature on the current healthcare crises including the occurrence of mucormycosis in India and even highlights the shortcomings of the vaccination policy in the country.

Keywords: COVID-19, Indian Healthcare System, Vaccination Policy, Black Fungus, Descriptive Analysis, Policymakers.

This is an Open Access article distributed under the terms of the Creative Commons Attribution Non-Commercial License (http:// creative commons. org/licenses/by-nc/4.0) which permits unrestricted non-commercial use, distribution, and reproduction in any medium, provided the original work is properly cited.

\section{INTRODUCTION}

The Corona virus (CoV) belongs to a wide family of viruses, which has been responsible for serious pulmonary illnesses and even fatality. Some of them are Severe Acute Respiratory Syndrome (SARS) in 2002 \& 2003 and Middle-east Respiratory Syndrome (MERS) in 2012. In December 2019, cases similar to SARS and MERS, were reported in Wuhan city of China, where identified as novel Corona virus 2019. Later the infection caused by this virus was named as COVID-19. In 2020, World Health Organization (WHO), declared it as an emergency and confirmed the pandemic. According to the current report of the WHO, there are around 16 million confirmed cases and nearly 3.5 million confirmed deaths as of $24^{\text {th }}$ May, 2021 globally. ${ }^{2}$

Developing countries are facing immense crises in different forms and at different levels of their health structure like primary, secondary and tertiary. India is one of those countries, which has been bearing both direct and indirect, several major consequences due to this current pandemic. As like many other countries, India is experiencing its second wave, the death toll and cases both are unprecedentedly high. It is the most critical time of Indian history as this disease has both the high infectivity and rates of transmission. ${ }^{3,4}$
This disease is transmitted from one person to another through human-to-human transmission in the air, which takes about 5-14 days to incubate. During this time symptoms such as shortness of breath, coughing, breathing difficulty, chest discomfort, fatigue, myalgia, confusion and it may affect tastebuds. In some serious conditions, oxygen deficiency causes blue lips and face and may require hospitalization. Initially, during the first wave serious complications were seen in elderly patients, but during the second wave young adults and children also reported many serious complications. ${ }^{5}$

The rising number of cases demands healthcare admissions and immediate treatment but the continuous increasing number of emergencies has been given rise to a considerable healthcare setback. The growing number of infectious cases demand hospital admissions thus require more bed, medications, oxygen concentrator, ventilators and other medical equipment. In the present pandemic situation, India needs a well-equipped healthcare system with a high number of well-trained medical professionals along with an accurate plan to counter the increasing cases and distribution of vaccines. Figure 1 shows confirmed cases; cumulative total from different states of India and Figure 2 shows the confirmed deaths in different states of India. Both data 


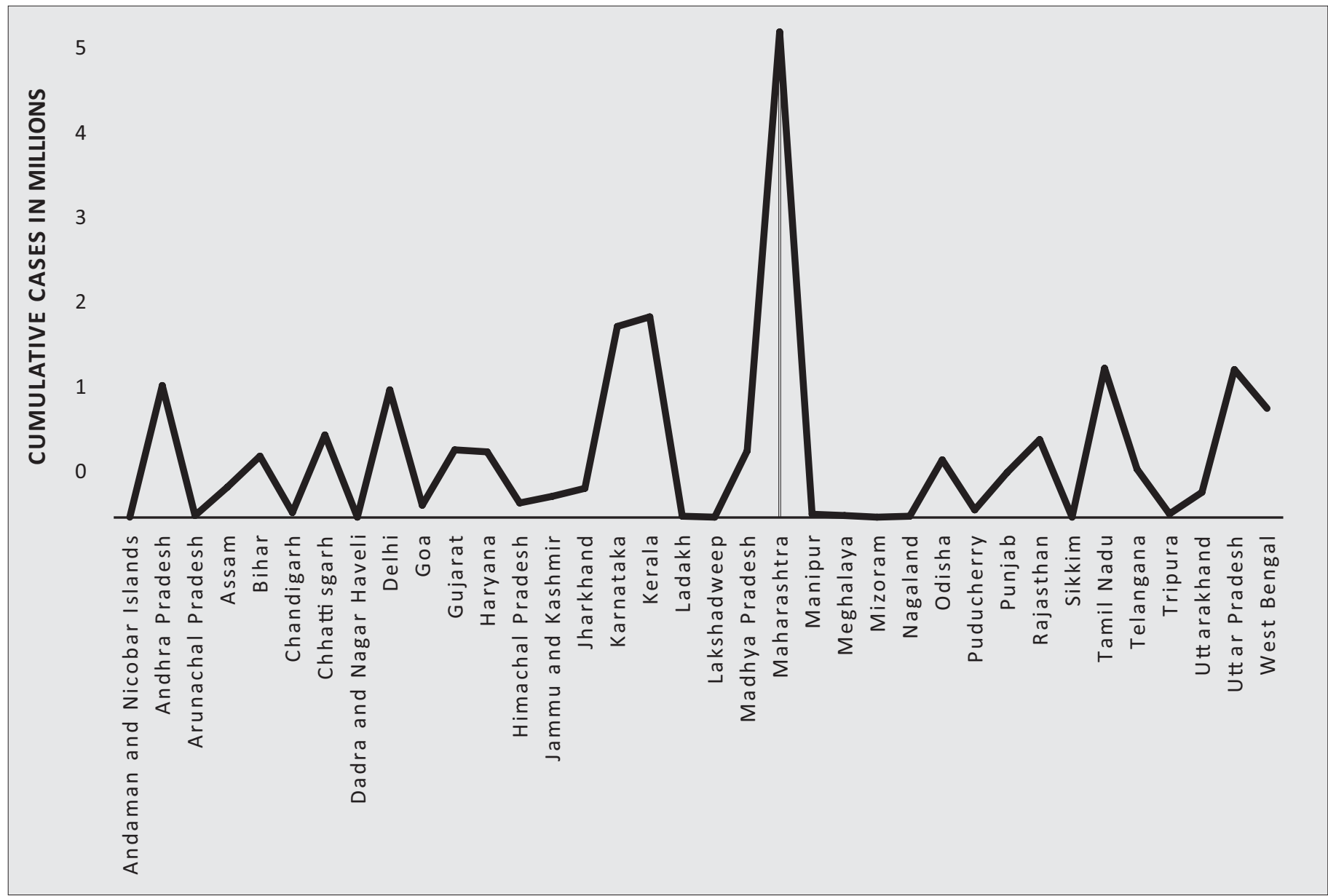

Figure 1. Cumulative total number of cases from some developing nations of the world. Source: Ministry of Health and Family Welfare, Government of India COVID19 dashboard, Author's representation.

are taken from Ministry of Health and Family Welfare COVID-19 dashboard as of $27^{\text {th }}$ May 2021.? Most deaths are attributed to co morbidities in COVID-19 patients. The lack of health infrastructure, particularly in semiurban and rural centers is one of the reasons behind the increased death rate.

\section{A WELL FUNCTIONING HEALTHCARE SYSTEM}

The healthcare has a comprehensive structure, which comprises of several component and sub-components. The different components come together to form the entire healthcare system. The services and management of each of these components vary individually but are interrelated and interdependent. Every country has its model for healthcare system. I In figure 3, author tries to show a model of wellfunctioning health system, which is given by the WHO and consists of six components: Leadership \& Governance, Health information system, Health financing, Human resource for health, Essential medical product and technologies, and Service delivery. ${ }^{8}$

A well-functioning health system is designed to fulfil the expectations of its population. A good function health system should:
* Focus on improving the health status of its individual.

* Defend the threats to the health of its population.

* Protect population from financial consequences due to diseases.

* Equitable access to care.

* Enabling its people to anticipate health and health system-related decisions. ${ }^{8-10}$

The components in the above model of health system show that each component is unique and interdepended and each component is essential and unique, suchas:

LEADERSHIP AND GOVERNANCE: Every country has its way of leadership and governance for the wellbeing of its population and transparency plays a major role in it. It is one of the most challenging and responsible components as a major part of the health system is dependent upon it. . $^{810}$

HEALTH INFORMATION SYSTEM: Good governance ensures good health information system which includes several components of transparency and timely intelligence like the flow of fund, health discussion \& meetings, and trends for $\mathrm{HRH} .^{9 \cdot 11}$ 


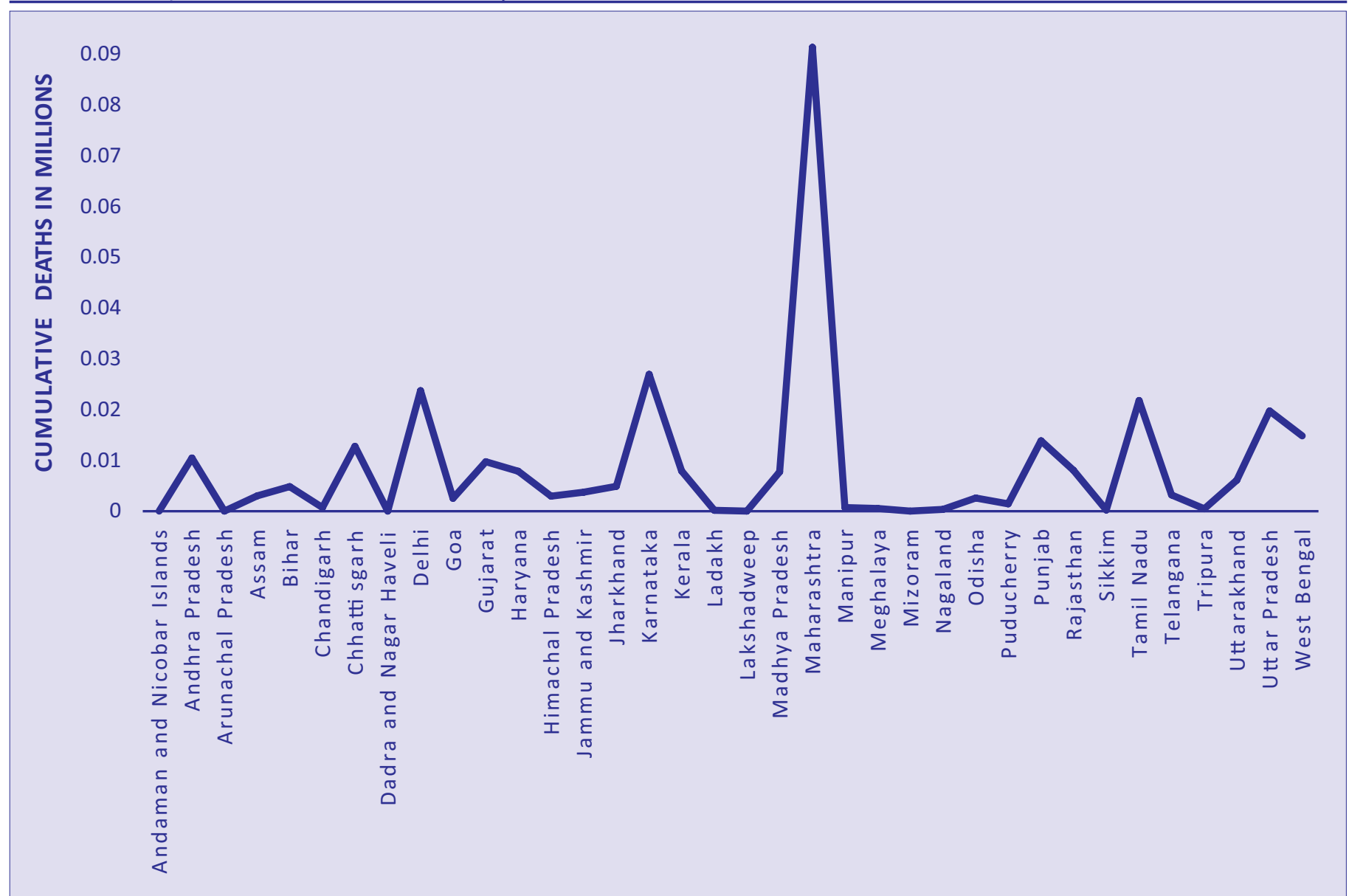

Figure 2: Shows the cumulative total deaths of some developing nation. Source: Ministry of Health and Family Welfare, Government of India dashboard, Author's representation.

HEALTH FINANCING: It is one of the key components for improving health and reducing health inequalities, it includes universal health coverage which prevents hardship and out-of-pocket expenditure. Government plays a major role in allocating funds to health, "the country is as healthy as the amount of health expenditure allocated to it its population". ${ }^{9 \cdot 11}$

HUMAN RESOURCE FOR HEALTH: Every country is at a different level of development but some of the common concern of every health care includes recruitment education, training and implementation..$^{9 \cdot 1}$

ESSENTIAL MEDICAL PRODUCTS AND RESPONSIBILITIES: Access to basic and affordable medicine, vaccines, diagnostics and other health services is dependent upon the allocation of funds by the government. . $^{-11}$

SERVICE DELIVERY: Health systems effective enough only when they provide effective services. Services include comprehensive, integrated, clinical and public health interventions. ${ }^{9-11}$

Comparing the Indian Healthcare system based upon these above components depicts the picture of Healthcare crises being faced by India during the current scenario of COVID-19. India needs to improve its health system strategies and strengthening every component of the healthcare system. ${ }^{9-1}$

\section{CRISES IN THE HEALTHCARE SYSTEM IN INDIA}

COVID-19 crises have immensely affected different sectors of our very important healthcare system thereby affecting its different components in most of the regions of India and irrespective of its level of development. In some places, the Healthcare system was affected to a level that it was pronounced as healthcare collapse. In India, as shown in Figure 4, where the total cases have reached 2,46,33,951 with one of the highest death tolls of nearly 3,15,235 according to the Ministry of Health and Family Welfare, Government of India as of May 26th 2021 and vaccine coverage data shows that a total of $20,26,95,875$ people have received vaccination in India till $27^{\text {th }}$ May 2021. Considering the preparedness of the Indian healthcare system in different levels of healthcare like primary, secondary and tertiary in India is utilizing its best of its available resources to cater for the need of the situation. The major problem lies in the availability of resources in the entire nation. ${ }^{11}$ The scarcity of 


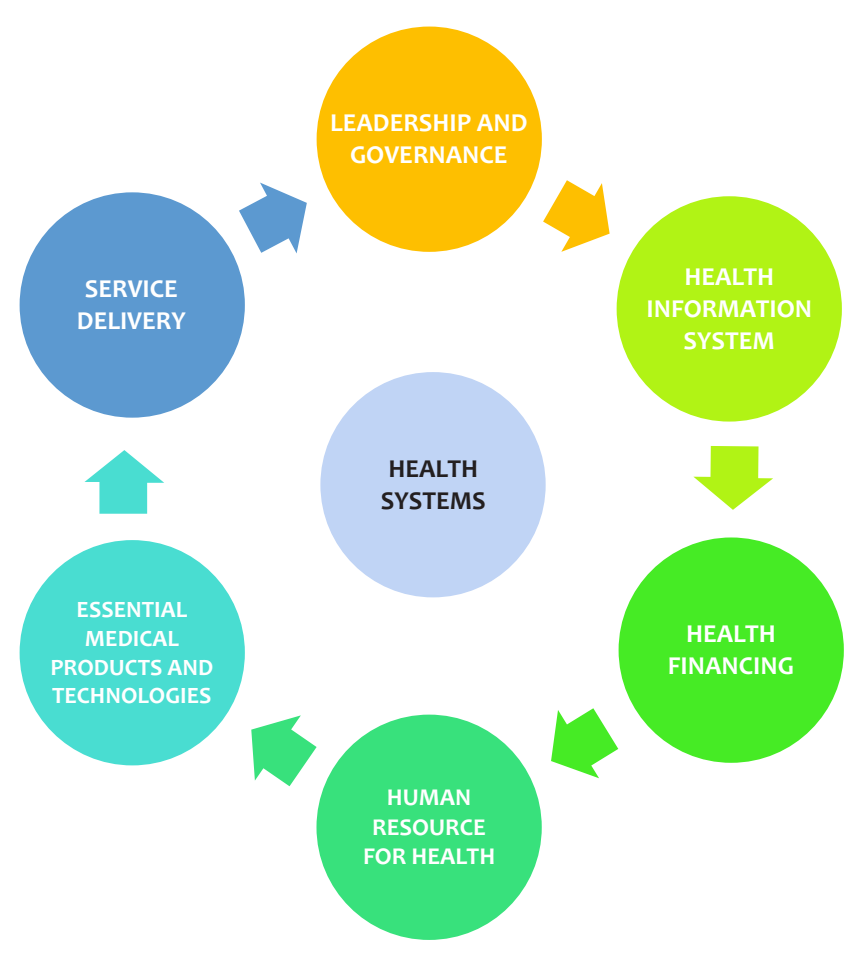

Figure 3: The Framework of Key components of Health care system source:World Health Organization. Author's representation.

essential medical products has increased the crises of the Indian Health system. It was estimated by The Indian Council of Medical Research (ICMR) that there are about 70,000 ICU Beds and fewer ventilators available. It was estimated in one of the studies that the number of cases increases by $15 \%$ everyday and the ICU admissions are growing likewise which creates unusual pressure on the authorities. The basic medicines supplies are scarce like medication, ventilators, ICU beds, oxygen cylinders and even COVID-19 vaccines. The situation demands more concern at every individual component of the healthcare system. The COVID-19 virus is virulent enough to cause infection to anyone irrespective of age, sex and type of work they perform. Therefore, the intervention needs to be scaled up to meet those demands. ${ }^{12-15}$

\section{COVID-19 VACCINATION COVERAGE AND CRISIS}

The Indian Health system, which is famous as produces vaccines in the entire world and contributes about $60 \%$ of Global vaccines. The COVAXIN is India's first inactivated vaccine developed by Bharat Biotech and Coveshield vaccines developed by Oxford University and Astra Zeneca (AZD1222) manufactured by Serum Institute collaboration. It was estimated by the Department of Biotechnology, India that India holds the capacity to manufacture 70-100million doses in a month, but the scenario looks different in present days.

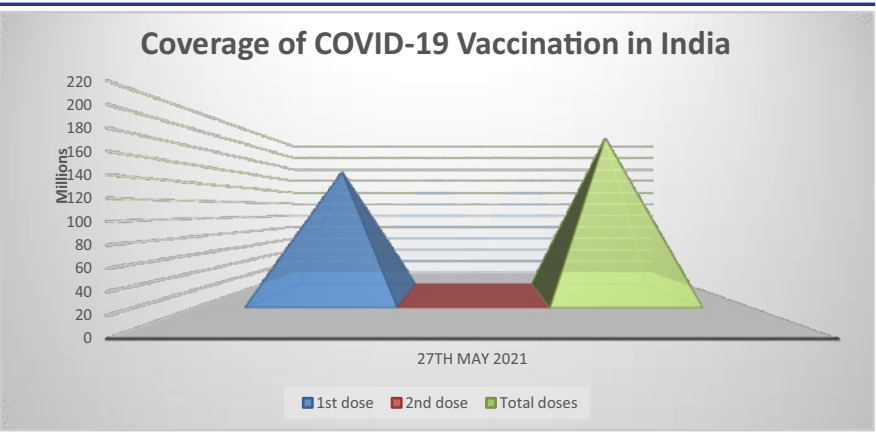

Figure 4. COVID-19 vaccination coverage in India, till $27^{\text {th }}$ May 2021. Source: Ministry of Health and Family Welfare, Government of India, Cumulative coverage report COVID-19 Vaccination, Author's representation

Coveshield and COVAXINE are the two widely given vaccine in different parts of India. India is one of the manufacturers of vaccine had also exported about 35.79 million doses to other countries, which now questions its scarcity when there is a shortage for its countrymen of the most susceptible age groups 45 years and above. This shortage has forced individual state governments like the Government of Odisha, Maharashtra, etc. to import vaccines from other countries. The vaccines falling short was even due to the failure of the vaccination coverage drive, which made vaccines available to people of different age groups holding a strong reference and this almost covered a great number of the population. India having the capability of manufacturing a cost-effective vaccine on large scale can not only help its countrymen getting vaccinated within a short span, but it will also help fulfil the global vaccine requirement without any economic crises. $^{14-16}$

It was estimated on $27^{\text {th }}$ May 2020 that there were 5,488 825 cases and 349,095 deaths globally and on $27^{\text {th }}$ May 2021, there have been $169,404,850$ cases and 3,519,085 deaths of COVID-19 worldwide, as of WHO. As the number of cases is increasing so is the seriousness of the situation and increasing demand for health care. There have been numerous studies made so far which talks about the rising toll of COVID-19 deaths, source of its transmission, diagnosis \& treatment and identifying the high-risk population and it was also suggested by experts that people above 50years and above are at higher risk of getting the infection, which is not the case these days as every individual coming in contact with the infected individual is susceptible of acquiring the infection. As the cases of infection are rising with time in the country there is also a rise in the severity of the disease. Several studies suggest that people with preexisting diseased conditions, especially individual with chronic disease are at high risk of developing severe 
Rath et al. COVID-19: A Burden on the Indian Healthcare System

infection. It has also been proved that diabetic patients with a high dosage of glucocorticosteroid develop another rare infection known as "Black fungus", widely occurring in India. ${ }^{17-18}$

\section{BLACK FUNGUS}

The severe conditions of Coronavirus (COVID-10) are being managed with glucocorticoids which gives rise to rare fungal infection among patients. There is evidence from hospital-based studies that mucormycosis or black fungus infection has been developed in patients admitted for severe COVID-19. Mucormycosis develops 10-14 days post-hospitalization. There is also evidence that proves glucocorticoids therapy increases the risk as the virus itself is an immunosuppressor and COVID19 affected individuals already have a compromised immune system. This infection of sinusitis is often lifethreatening and sometimes difficult to treat. The rising cases of Black fungus in India are making it difficult to treat and increasing the number of deaths in few states which include Maharashtra, Gujrat, Odisha, Tamil Nadu, etc which is experiencing a peak of COVID19 infection. More than 11000 cases of mucormycosis have been reported till now from India. The efficiency of the healthcare system should be increased to gain immediate control over the situation. ${ }^{17-18}$

\section{DISCUSSION}

The COVID-19 is going to stay with us longer and the only way of gaining protection against it is to develop herd immunity. This immunity can only be achieved when vaccination is done in large numbers otherwise known as "mass vaccination". The cases of COVID-19 are rising and the demand for healthcare is increasing. There is a scarcity of certain valuable resources which brings challenges for the suppliers. There have been various initiatives by the individual states to meet the shortage of hospital beds and availability of oxygen ventilators for the patients still this not sufficient enough. Though efforts have been shown on various grounds by both centre and state government and administrators there need to be a more effective solution for the changing scene before the arrival of the third wave.

Among all the public health interventions the development of Vaccines is a commendable achievement by the Government of India. The COVAXINE and COVIESHEILD vaccine was a remarkable move by India but the strategy towards achieving a maximum of $60 \%$ vaccination by December 2021 requires more refinement and improvement which can be incorporated through introducing advanced practices of monitoring and supervision. There is a strong hope that the epidemic will be under control up to a certain level at a certain time but the administration at different components of the healthcare system is essential for a certain period is essential. ${ }^{13-15}$ The government of India has also worked with lots of effort for taking maximum precautions and meeting healthcare needs. There needs to be more improvement at the grassroots level for the allocation of resources and monitoring of resources allocated to prevent scarcity of medical equipment..$^{19-21}$

COVID-19 pandemic has impacted every sector of India has exposed India in all possible ways. From migrant workers to health infrastructure and vaccine policy. Existing systems failed and were a big reality check to the government and all Indian citizens. The inadequacy of health infrastructure, trained medical personnel and policymakers in India was quite obvious during the second wave management. The government had to reevaluate and radically improve the public healthcare, infrastructure to manage this crisis and prevent the threat of the third wave. Prevention of disease became the priority rather than management of the disease.

\section{CONCLUSION}

The increasing COVID-19 cases are demanding more essential medical resource which is leading to scarcity. This paper is a detailed analysis of the current situation it also talks about various key components of the healthcare system and its importance and as of the current situation demands that every component requires special attention of the policymakers, as the most essential resources are depleting and it might not take much longer for the resources to get overwhelmed within a very short span. This paper is a detailed study of the current situation and focuses on managing or gaining control over the current scenario of COVID19. India being a vast country with a large population, it is a herculean task for any government to address the needs of every individual, but the fact cannot be denied that, from the time of independence, the health sector has not received its due priority, which can be felt today in this pandemic.

ETHICALAPPROVAL: Not required.

AUTHORS' CONTRIBUTION: NA: Drafting and literature search. SR: Conceptualization, data collection and final editing.

CONFLICTS OF INTEREST: Author declares no conflicts of interest.

FUNDING: Nil. 


\section{REFERENCES}

1. Liu J, Xie W, Wang Y, Xiong Y, Chen S, Han J, et al. A comparative overview of COVID-19, MERS and SARS: Review article. Int J Surg 2020; 81:1-8.

doi:10.1016/j.ijsu.2020.07.032

2. Akhtar N, Rath S, Das SR, Dubey D. COVID-19 pandemic: global scenario, social determinants and its socioeconomic impact. European J Molecular Clin Medi 2020; 7: 4860-72.

3. Athar M. Current Circumstances of Corona-Virus (Covid-19) in India. Int Arch Public Health Community Med 2020; 4:038.

doi.org/10.23937/2643-4512/1710038

4. Pathak SK, Pandey S, Pandey A, Salunke AA, Thivari P, Ratna HV, et al. Focus on uncommon symptoms of COVID-19: Potential reason for spread of infection. Diabetes Metab Syndr 2020; 14:1873-4. doi:10.1016/j.dsx.2020.09.017

5. Agrahari R, Mohanty S, Vishwakarma K, Nayak SK, Samantaray D, Mohapatra S. Update vision on COVID19: Structure, immune pathogenesis, treatment and safety assessment. Sensors Int 2021; 2:100073. doi.org/10.1016/j.sintl.2020.100073

6. Sv P, Lathabhavan R, Ittamalla R. What concerns Indian general public on second wave of COVID-19? A report on social media opinions. Diabetes Metab Syndr 2021; 15:829-30. doi:10.1016/j.dsx.2021.04.001

7. Available at: https://www.mohfw.gov.in (Last accessed on $24^{\text {th }}$ May 2021)

8. Suter E, Oelke ND, Adair CE, Armitage GD. Ten key principles for successful health systems integration. Healthc Q 2009; 13:16-23. doi: $10.12927 /$ hcq.2009.21092

9. Strickland BB, Jones JR, Newacheck PW, Bethell CD, Blumberg SJ, Kogan MD. Assessing systems quality in a changing health care environment: the 2009-10 national survey of children with special health care needs. Matern Child Health J 2015;19:353-61.

doi: 10.1007/s10995-014-1517-9

10. Manyazewal T. Using the World Health Organization health system building blocks through survey of healthcare professionals to determine the performance of public healthcare facilities. Arch Public Health 2017; 75:50. doi:10.1186/s13690-017-0221-9
11. Ghosh A, Nundy S, Mallick TK. How India is dealing with COVID-19 pandemic. Sensors International 2020; 1:100021. doi.org/10.1016/j.sintl.2020.100021

12. Shadmi E, Chen Y, Dourado I, Faran-Perach I, Furler J, Hangoma P, et al. Health equity and COVID-19: global perspectives. Int J Equity Health. 2020 Jun 26; 19:104. doi: 10.1186/s12939-020-01218-z

13. GRID COVID-19 Study Group. Combating the COVID-19 pandemic in a resource-constrained setting: insights from initial response in India. BMJ Glob Health 2020; 5:e003416. doi:10.1136/bmigh-2020-003416

14. Jabaris SL, Ananthalakshmi V. The current situation of COVID-19 in India. Brain Behav Immun Health 2021; 11:100200. doi:10.1016/j.bbih.2021.100200

15. Dhar R, Jee B, Karmakar S. Balancing Healthcare and economy amidst the covid-19 pandemic: an Indian experience. Risk Manag Healthc Policy 2021; 14:82733. doi: 10.2147/RMHP.S291084

16. Goel I, Sharma S, Kashiramka S. Effects of the COVID-19 pandemic in India: An analysis of policy and technological interventions. Health Policy Technol 2021;10:151-64. doi:10.1016/j.hlpt.2020.12.001

17. Garg D, Muthu V, Sehgal IS, Ramachandran R, Kaur H, Bhalla A, et al. Coronavirus Disease (Covid-19) Associated Mucormycosis (CAM): Case Report and Systematic Review of Literature. Mycopathologia 2021; 186:289-98. doi: 10.1007/s11046-021-00528-2

18. Sharma S, Grover M, Bhargava S, Samdani S, Kataria T. Post coronavirus disease mucormycosis: a deadly addition to the pandemic spectrum. J Laryngol Otol 2021;135:442-7. doi:10.1017/S0022215121000992

19. Farsalinos K, Poulas K, Kouretas D, Vantarakis A, Leotsinidis M, Kouvelas D, et al. Improved strategies to counter the COVID-19 pandemic: Lockdowns vs. primary and community healthcare. Toxicol Rep. 2021; 8:1-9. doi:10.1016/j.toxrep.2020.12.001

20. Jayamani J, Thangaraju P, Thangaraju E, Venkatesan S. Decentralisation of the healthcare system due to COVID-19 and its impact on hospital-based laboratories - Pandemic panic patients' reflection?. J Responsible Technol 2020; 1:100003.

21. Garg S, Bhatnagar N, Singh MM, Borle A, Raina SK, Kumar R, et. al Strengthening public healthcare systems in India; Learning lessons in COVID-19 pandemic. J Family Med Prim Care 2020; 9:5853-7. doi: $10.4103 /$ jfmpc.jfmpc_1187_20 